\section{New Year, New Look!}

$\mathbf{B}^{y}$ the time you read this, you have probably gained a few pounds from eating holiday treats, spent too much money on gifts and entertainment, failed to adhere to your exercise program, and are generally feeling critical of yourself. Or is that just me? Anyway, it's time for the annual effort to make new resolutions with a focus on self-improvement. Go for it!

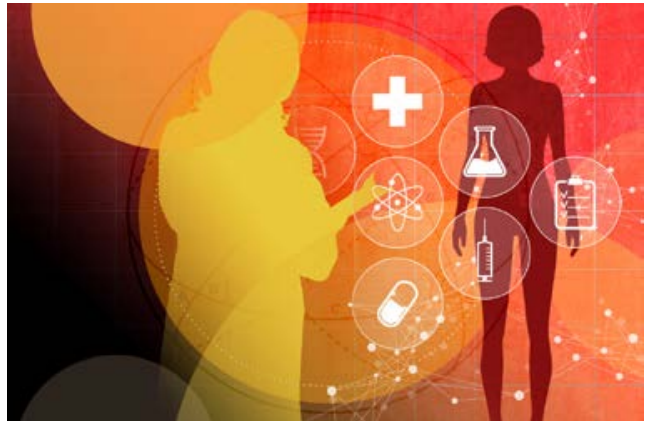

At JNCCN, we got a head start on improving our image months ago. In an effort to make the journal more pleasing and interesting to read, we've redesigned the journal's look; we hope you'll enjoy the changes. Among other things, we have reorganized the table of contents, streamlined some pages, and changed some of the color blocks. But for me, the

biggest and most important change is the addition of cover art.

Since the journal's inception, the cover of each issue of JNCCN has featured photos of an NCCN Member Institution and some of their leadership. At recent NCCN committee meetings, we heard from a number of people, including the NCCN Guidelines Panel Chairs, that this didn't do much for them. One even said that he thought it somehow minimized the importance of the journal. We took those comments to heart and began to think about what we might do instead.

One of my favorite periodicals is The New Yorker, and I am always intrigued by the cover art. Sometimes it's just fun to look at, but often there is a powerful message within the image. So I suggested we think about an artistic reference to the guideline we feature in each issue. Our publishing team at Harborside identified a talented artist, Stephanie Dalton Cowan, who has the ability to transform a technical topic into a fascinating image that will make you stop and think.

In this issue, we are publishing the updated NCCN Guidelines for Cervical Cancer, and I believe Stephanie took a tasteful approach to depict this topic. We are thrilled to share this with you. And stay tuned. There will be a new image on each new issue.

In closing, I send you all my best wishes for a Happy (and rewarding) New Year. This will be a good one; I just know it! JNCCN@nccn.org or log into www.editiorialmanager.com/JNCCN.

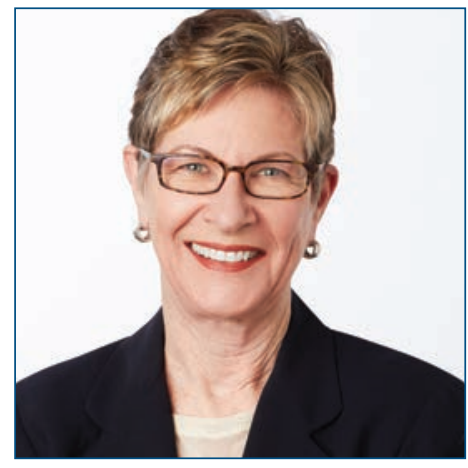

MARGARET TEMPERO, MD

Margaret Tempero, MD, is a Professor of Medicine and Director of the UCSF Pancreas Center and editor-in-chief of JNCCN. Her research career has focused on pancreatic ductal adenocarcinoma, especially in the area of investigational therapeutics. Dr. Tempero has served on the ASCO Board of Directors and as ASCO President. She currently serves on the ASCO Conquer Cancer Foundation Board. She codirected the AACR/ASCO Methods in Clinical Cancer Research and taught this course and similar courses in Europe and Australia. She was founding Chair of the $\mathrm{NCl}$ Clinical Oncology Study Section and served as a member and Chair of the $\mathrm{NCl}$ Board of Scientific Counselors Subcommittee A. She is a member of the Scientific Steering Committee and Chair of the Clinical and Translational Study Section for the Cancer Prevention \& Research Institute of Texas. She is or has been on the Scientific Advisory Boards of the Lustgarten Foundation, the Pancreatic Cancer Action Network, the V Foundation, The Alberta Canada Cancer Board, and the EORTC. She served as a member of the Oncology Drug Advisory Committee for the FDA. She has served as Deputy Director and Interim Director for the UNMC Eppley Cancer Center. She is Chief Emeritus of the Division of Medical Oncology at UCSF and served as the founding Deputy Director and Director of Research Programs at the UCSF Helen Diller Family Comprehensive Cancer Center.

doi: 10.6004/jnccn.2019.0003

The ideas and viewpoints expressed in this editorial are those of the author and do not necessarily represent any policy, position, or program of NCCN. 